\title{
$\mathrm{HIP}$ 공정이 $\mathrm{PBF}$ 기반 스테인리스강 $316 \mathrm{~L}$ 적층 소재의 피로 성능에 미치는 영향
}

\author{
오동진 ${ }^{*, \dagger}$ - 강용준 ${ }^{* *}$ - 김기동**,*** - 박소영******** 송상우 ${ }^{* *}$ \\ *한국기계연구원 부설 재료연구소 원자력공인검사단 \\ **한국기계연구원 부설 재료연구소 접합기술연구실 \\ ***울산과학기술원 원자력공학과 \\ *****창원대학교 신소재공학부
}

\section{Effect of HIP Process on Fatigue Performance for SS 316L Manufactured by PBF}

\author{
Dongjin $\mathrm{Oh}^{* \dagger} \dagger$, Yongjoon Kang**, Gidong Kim**,***, Soyoung Park**,**** and Sangwoo Song** \\ *Authorized Nuclear Inspection Department, Korea Institute of Materials Science (KIMS), \\ Changwon, 51508, Korea \\ **Joining Technology Department, Korea Institute of Materials Science (KIMS), Changwon, 51508, Korea \\ ***Department of Nuclear Engineering, Ulsan National Institute of Science and Technology (UNIST), \\ Ulsan, 44919, Korea \\ ****Department of Materials Science and Engineering, Changwon National University, Changwon, 51140, Korea
}

†Corresponding author : odj3315@kims.re.kr

(Received January 16, 2020 ; Revised February 4, 2020 ; Accepted February 17, 2020)

\begin{abstract}
Additive manufacturing (AM) is an interesting technology with the potential to replace general fabrication techniques such as machining, forming and casting. AM provides two main benefits: greater freedom of part design and lower material consumption. To improve quality, many researchers have investigated the mechanical characteristics of AM products and additive parameters. In the present study, tensile and fatigue tests were conducted on stainless steel (SS) 316L manufactured using powder bed fusion (PBF) technology. These tests were carried out using two different building directions, along the $\mathrm{Z}$ and $\mathrm{X}$ axis, to investigate the effect of additive direction. In addition, the effects of hot isostatic pressing (HIP) related to fatigue properties, which can influence the volume density and porosity of the specimen, was studied. Based on the test results, changes in the mechanical characteristic and fatigue strength due to the HIP treatment were investigated.
\end{abstract}

Key Words : Additive manufacturing, Fatigue test, Stainless steel 316L, Powder bed fusion, Hot isostatic pressing

\section{1. 서 론}

4차 산업혁명 시대를 이끌어갈 핵심 기술 중 하나인 적층제조(additive manufacturing, $\mathrm{AM}$ ) 기술은 기 존의 제조공법과 달리 다양한 적층방법을 통해 기계 부 품을 생산하는 기술로서 자동차, 우주/항공, 조선 등 전 산업분야에 걸쳐 큰 영향을 끼치고 있다 ${ }^{1,2)}$. 특히,
금속 적층 제조 기술은 원소재의 불필요한 부분을 제거 함으로써 하나의 부품을 제작, 생산하는 절삭가공 기술 과 달리 3 차원 형상의 프린팅을 통해 부품을 설계, 제 작하므로 원가 절감이 가능하다. 금속 적층에는 기판 위에 도포되어 있는 분말에 레이저나 전자빔을 조사하 여 부품을 제작하는 powder bed fusion $(\mathrm{PBF})$ 방식 과 열원과 분말 또는 와이어를 함께 분사하여 적층하는 direct energy deposition(DED) 방식이 주로 사용되

Journal of Welding and Joining, Vol.38 No.1(2020) pp41-46

https://doi.org/10.5781/JWJ.2020.38.1.4 
고 있다 ${ }^{3,4)}$. 산업계에서는 적층되는 부품의 용도와 목 적에 맞게 상기 적층 공정 중 적절한 방법을 선택하고 있으며, 공정 최적화를 통해 기계적 강도가 높은 적층 소재를 만들기 위한 연구를 활발히 수행하고 있다 ${ }^{5,6)}$.

본 연구에서 평가하고자 하는 $\mathrm{PBF}$ 기반 적층 공정 은 정밀성이 우수한 장점으로 인해 다양한 분야에서 적 용되고 있으며, 적층공정 후에 적층소재 내부에 존재하 는 기공을 제어하기 위해 열간 등압 성형 (hot isostatic pressing, $\mathrm{HIP}$ ) 공정을 수행하고 있다. $\mathrm{PBF}$ 공정을 적용한 적층 소재들의 신뢰성 확보 및 실용화를 위해서 는 적층 방향과 $\mathrm{HIP}$ 공정 적용에 의해 변화하는 기계 적 물성들의 평가는 필수적이다. 이에 국내외 연구기관 에서는 적층 소재의 경도, 인장 강도, 연신율 등의 일 반적인 기계적 강도뿐만 아니라 구조물 설계에 있어 필 수적 요소인 피로, 파괴 특성을 분석하기 위한 연구들 을 진행하고 있다 ${ }^{5-8)}$. 특히, 적층 속도, 해치 간격, 레 이저 파워 등 적층 소재의 특성과 내부 기공에 영향을 미치는 공정 변수들의 변화에 따른 기계적 특성을 평가 하는 연구가 최근까지 수행되었다 ${ }^{9,10)}$. 또한, 실제 구조 물에 Ti alloy, stainless steel, Ni alloy 분말로 제 작한 적층 부품을 적용하기 위해 소재의 장기물성 평가 를 수행하고 있다 ${ }^{6)}$. 하지만, 국내의 경우 장기 물성 평 가 구축과 관련하여 아직 초기 단계에 머물러 있으며, 적층 부품들의 적용성 확보를 위해 장기물성 평가에 대 한 연구가 시급한 상황이다.

본 연구에서는 적층 소재 장기물성 평가 관련 기초 연구를 위해 레이저 $\mathrm{PBF}$ 공정으로 제작한 stainless steel(SS) $316 \mathrm{~L}$ 소재의 피로 강도를 평가하였다. 또 한, 적층 방향에 따른 기계적 물성 및 피로 강도 변화 와 후처리 공정 적용에 피로 특성을 분석하였다.

\section{2. 사용 재료}

\section{1 분말 조성 및 미세조직}

본 연구에서는 적층 소재 제작을 위해 SS 316L 상 용 분말인 concept laser사의 CL 20ES 분말과 M1 장비를 사용하였으며, 분말의 화학적 조성은 Table 1 에 정리하였다. 적층 소재의 기계적 물성에 영향을 미 치는 레이저 파워, 적층 속도 및 두께와 같은 적층 조 건들은 Table 2에 정리하였으며, 적층 방법은 Fig. 1 과 같이 각 layer가 직교하게 적층되는 방법을 적용하
Table 2 Additive manufacturing parameters of test specimen

\begin{tabular}{|c|c|c|c|c|}
\hline $\begin{array}{c}\text { Power } \\
(\mathrm{W})\end{array}$ & $\begin{array}{c}\text { Scan } \\
\text { speed } \\
(\mathrm{mm} / \mathrm{s})\end{array}$ & $\begin{array}{c}\text { Layer } \\
\text { thickness } \\
(\mathrm{mm})\end{array}$ & $\begin{array}{c}\text { Hatch } \\
\text { spacing } \\
(\mathrm{mm})\end{array}$ & $\begin{array}{c}\text { Energy } \\
\text { density } \\
(\mathrm{J} / \mathrm{mm} 3)\end{array}$ \\
\hline 180 & 600 & 25 & 0.15 & 111.1 \\
\hline
\end{tabular}

Table 3 Condition of HIP process

\begin{tabular}{|c|c|c|}
\hline $\begin{array}{c}\text { Holding time } \\
(\mathrm{hr})\end{array}$ & $\begin{array}{c}\text { Temperature } \\
\left({ }^{\circ} \mathrm{C}\right)\end{array}$ & $\begin{array}{c}\text { Heating rate } \\
\left({ }^{\circ} \mathrm{C} / \mathrm{min}\right)\end{array}$ \\
\hline 4 & 1,125 & 10 \\
\hline
\end{tabular}

Layer $n-2$

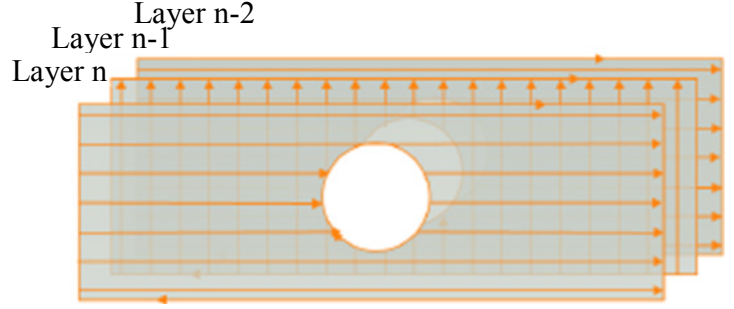

Fig. 1 Scanning strategy of test specimens

였다. 소재 내부의 기공 제어를 위해 적용하는 후처리 공정인 $\mathrm{HIP}$ 을 적용하여 시편을 제작하였으며, HIP 조 건을 Table 3에 나타내었다. 이때, 유지시간 및 온도 는 ASTM F3184 ${ }^{11)}$ 에서 제시하고 있는 HIP 공정 요 건을 만족하였다.

\section{3. 실험 방법 및 결과}

\section{1 실험 방법}

적층방향에 따른 기계적 물성 변화를 평가하기 위해 Fig. 2와 같이 Z 방향(vertical direction)과 $\mathrm{Y}$ 방향 (horizontal direction)으로 봉상 적층 시편을 제작하 였다. 이때, 시험편은 기존 봉상 적층 시편을 기계 가 공하여 $\mathrm{ASTM} \mathrm{E} 8^{12}$ 과 $\mathrm{E} 466^{13)}$ 에서 제시하고 있는 환 봉 형상 표준시험편으로 제작하였으며, 상세 크기는 Fig. 3에 정리하여 나타내었다. 또한, HIP에 따른 경도 변 화를 분석하기 위해 시험편 하단부에서 시편을 채취하 여 경도를 측정하였다. 피로시험은 하중제어로 수행하였 으며, 파형은 정현파, 응력비 0.1 , 주파수 범위 10 $15 \mathrm{~Hz}$ 에서 시험을 수행하였다. 피로 한도는 $2,000,000$ cycle로 시험편이 상기 cycle까지 파단이 되지 않을 경 우 시험을 중단하였다.

Table 1 Chemical composition of SS 316L powder (unit : \%)

\begin{tabular}{|c|c|c|c|c|c|c|c|c|}
\hline $\mathrm{Cr}$ & $\mathrm{Ni}$ & $\mathrm{Mo}$ & $\mathrm{Mn}$ & $\mathrm{Si}$ & $\mathrm{P}$ & $\mathrm{C}$ & $\mathrm{S}$ & $\mathrm{Fe}$ \\
\hline $16.5-18.5$ & $10.0-13.0$ & $2.0-2.5$ & $<2.0$ & $<1.0$ & $<0.045$ & $<0.03$ & $<0.03$ & Balance \\
\hline
\end{tabular}




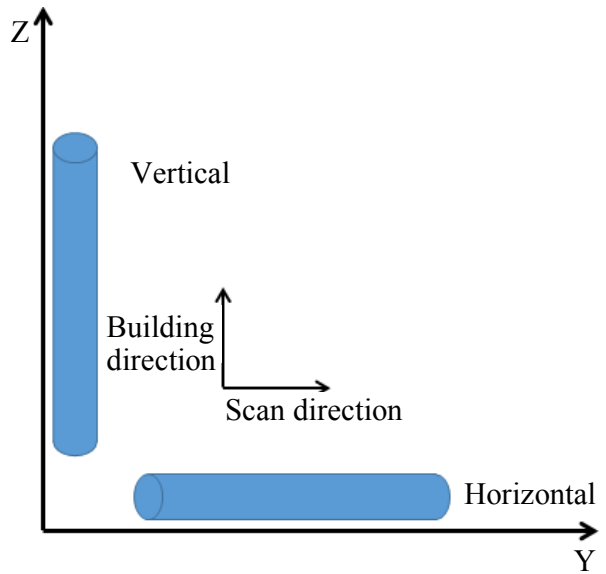

Fig. 2 Building direction of test specimens
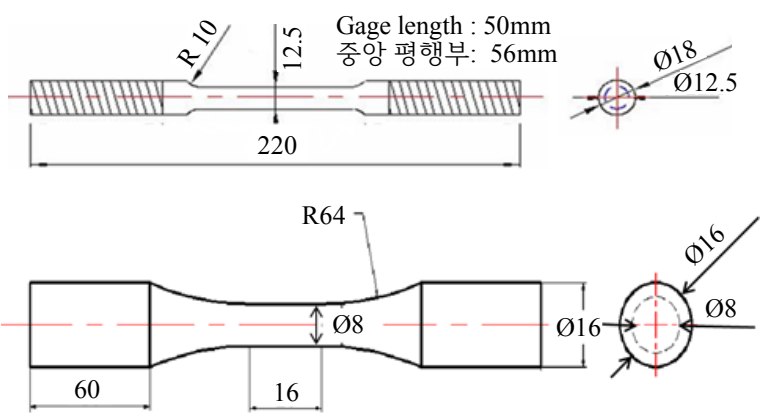

Fig. 3 Dimension of tensile and fatigue test specimen

\section{2 실험 결과}

적층 소재 기계적 물성 평가에 앞서, 적층방향에 따 른 조직 특성을 분석하기 위해 optical microscopy $(\mathrm{OM})$ 를 통해 미세조직을 관찰하였다. Fig. 4와 5에 나타난바와 같이, $\mathrm{Z}$ 방향으로 적층된 시험편의 수직한 면(1) 방향)을 관찰한 결과 적층 제조 시험편에서 전형 적으로 나타나는 바둑판 무늬가 확인되었다. 또한, 적 층 방향에 수평한 면(2) 방향)에서는 용융풀 경계가 선 명하게 관찰되었다. 이와 마찬가지로, $\mathrm{Y}$ 방향으로 적층 한 시편의 수직, 수평한 면 모두(1), (2)방향)에서 용융 풀 경계가 선명하게 나타났다. 하지만, HIP 공정 적용 후에는 방향성이 사라지는 것을 확인 할 수 있다. 이를 통해, 고온, 고압인 HIP 공정에 의해 미세조직 재결정 이 일어났으며, 적층방향에 의한 이방성이 사라짐으로 써 소재의 균질화가 이뤄졌음을 알 수 있다.

HIP 처리에 따른 강도 변화를 분석하기 위해 적층 시편의 경도를 측정하였다. 경도는 적층방향과 수직한 면에 $500 \mathrm{~g}$ 의 하중을 부하하여 측정하였다. 또한, 적층 면에 6 개의 임의의 위치에서 경도를 측정하였으며, 측 정값 중 최대, 최소, 평균 경도를 Table 4에 정리하였 다. 비교 결과, $\mathrm{Z}, \mathrm{Y}$ 적층 방향에 따른 경도 차이는 미

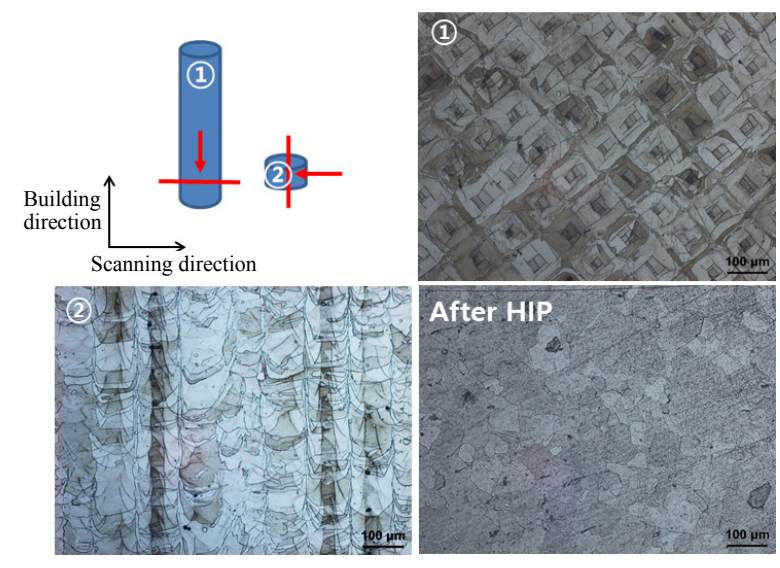

Fig. 4 Microstructure of $Z$ direction specimen

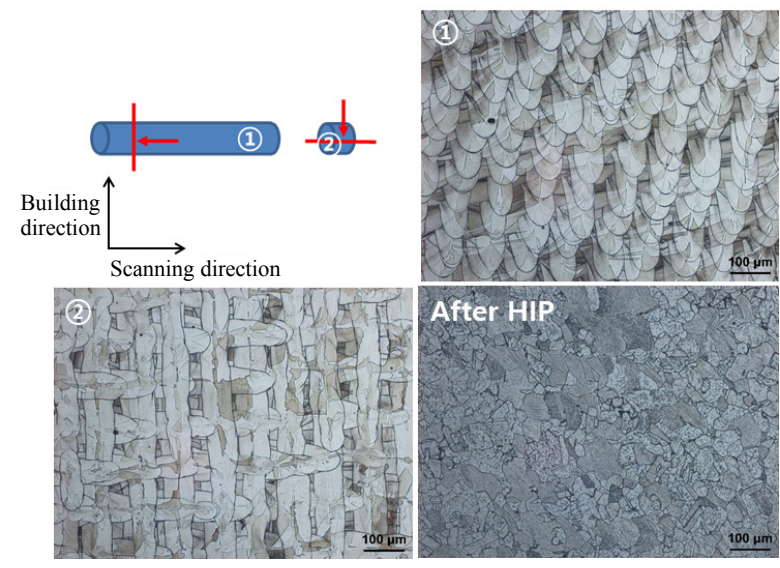

Fig. 5 Microstructure of Y direction specimen

Table 4 Measurement results of hardness (unit : Hv)

\begin{tabular}{|c|c|c|c|}
\hline $\begin{array}{c}\text { Building } \\
\text { direction }\end{array}$ & Max. value & Min. value & Avg. value \\
\hline Y & 255.7 & 240 & 241.6 \\
\hline Y_H & 169.9 & 164.9 & 167.9 \\
\hline Z & 251.5 & 244.3 & 245.4 \\
\hline Z_H & 187.5 & 173.3 & 179.6 \\
\hline
\end{tabular}

미하였으며, HIP 공정에 의해 적층 소재의 경도가 기존 대비 약 $60 \sim 70 \mathrm{Hv}$ 정도 감소하였다. 이는, $\mathrm{HIP}$ 공정 에 의해 조직의 재결정이 발생함에 따라 전위밀도가 감 소하였기 때문으로 판단할 수 있다 ${ }^{14,15)}$. 또한, HIP 공 정을 적용한 경우 적층방향에 상관없이 유사한 경도값 을 가짐을 확인하였다.

적층 소재의 $\mathrm{HIP}$ 전, 후 강도 변화를 분석하기 위해 ASTM E8에 따라 인장시험을 수행하였으며, 적층방향 과 후처리 공정 조건에 따라 각각 3 개의 시험편을 시험 에 사용하였다. 이때, Fig. 6과 같이 수직방향 적층 시 험편은 적층면과 하중 작용 방향이 수직이며, 수평방향 


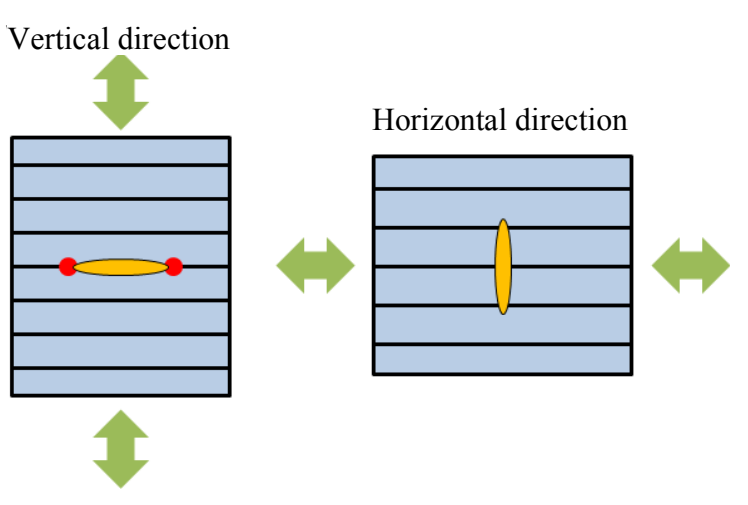

Fig. 6 Loading direction with building direction

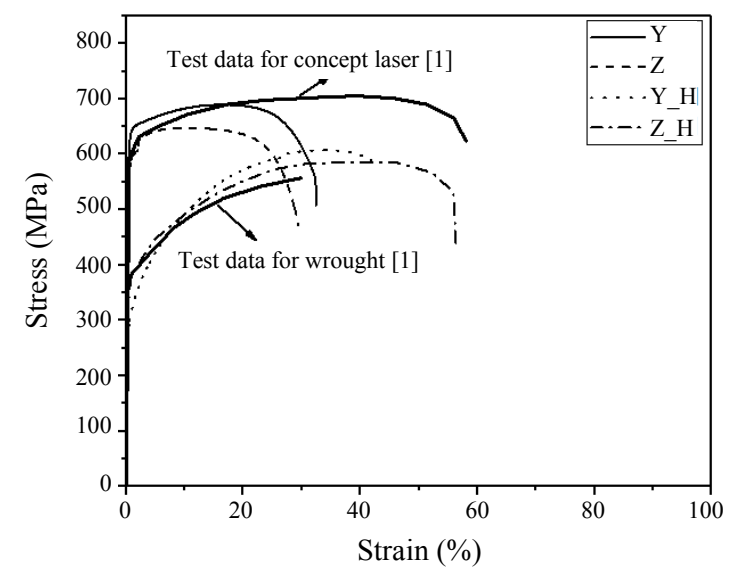

Fig. 7 Stress-strain curves for test specimens ${ }^{1)}$

적층 시험편은 적층면과 하중 작용 방향은 수평을 이룬 다. 인장 시험을 통해 얻어진 적층 방향 및 후처리 적 용 시편들에 대한 응력-변형률 선도를 Fig. 7에 나타내 었다. 이때, 다른 시험 결과와의 비교 분석을 위해 참 고 문헌 〔1〕에서 시험한 결과를 함께 정리하였다. Fig. 7에 나타난 바와 같이, $\mathrm{Y}$ 방향 에 대한 응력-변형률 선도가 Z 방향 선도보다 높으며, 최종 파단까지 변형률 은 비슷한 것으로 확인되었다. 또한, 다른 SS 316L의 인장시험 결과와 비교한 결과, 인장, 항복강도는 유사 하나 연신율은 현저하게 낮으며, 이는 적층공정의 차이 로 인해 발생한 것으로 판단된다. $\mathrm{HIP}$ 공정 적용에 따 른 차이의 경우, $\mathrm{Z}, \mathrm{Y}$ 방향의 응력-변형률 선도들이 비 슷하고 wrought 소재의 결과와 유사함을 확인하였다. 또한, 인장시험을 통해 얻어진 항복, 인장, 연신율의 평 균값을 Fig. 8에 정리하여 나타내었다. 분석 결과, 시 험을 통해 얻어진 항복, 인장, 연신율 모두 ASTM F3184 에서 제시하고 있는 최소 요건들을 만족함을 확인하였 다. 특히, $\mathrm{Y}$ 방향의 항복과 인장값들이 $\mathrm{Z}$ 방향보다 약 간 높았으나 연신율은 반대의 경향을 보이는 것을 확인 하였다. $\mathrm{HIP}$ 공정 적용에 따른 결과를 보면, 공정 적 용 전 결과들보다 항복, 인장은 낮으나 연신율은 크게 증

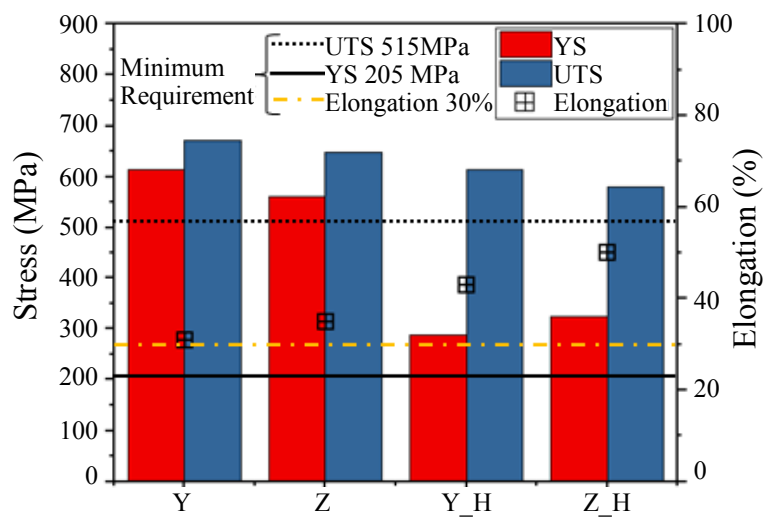

Fig. 8 Results of tensile test

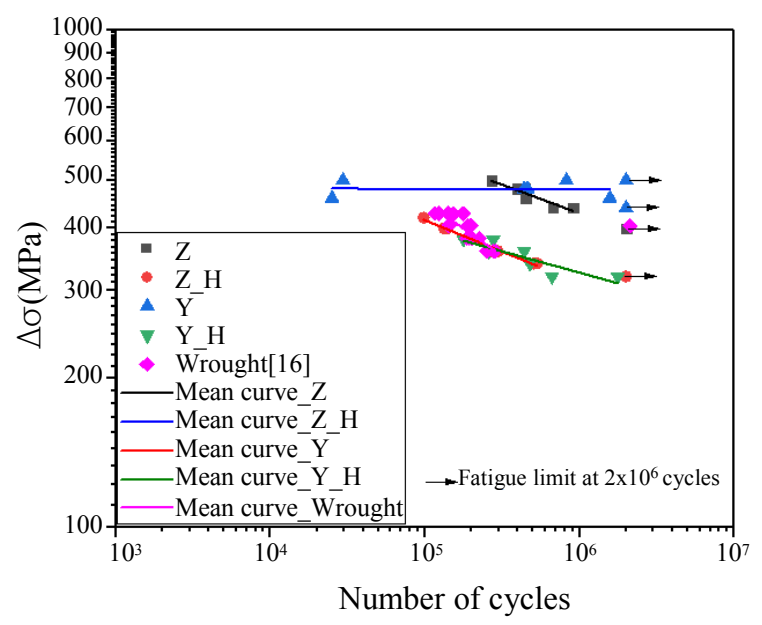

Fig. 9 S-N curves for $\mathrm{Z}$ and $\mathrm{Y}$ direction specimens ${ }^{16)}$

가하였다. 이러한 결과들은 Fig. 6 과 같이 하중 작용 방향과 적층면이 수직(Y 방향) 혹은 평행 ( $\mathrm{Z}$ 방향)하는 지에 따라 나타났으며, 일반적으로 논의되는 적층방향에 의한 인장시험 결과들과 동일함을 알 수 있다 ${ }^{5,6)}$.

적층방향과 후처리 유무에 따른 피로 시험 결과를 Fig. 9에 정리하였다. 적층방향에 따른 피로 강도의 경우, $\mathrm{Z}, \mathrm{Y}$ 방향의 피로 강도가 wrought 소재의 피로 강도 보다 높고 각 방향의 피로 강도들은 비슷함을 알 수 있 다. 또한, $\mathrm{HIP}$ 공정을 적용한 적층 소재의 피로 강도 는 기존 적층 소재의 피로 강도보다 낮으며, 이는 인장 시험을 통해 얻어진 강도 특성과 유사함을 알 수 있다.

\section{4. 실험 고찰}

Scanning electron microscopy(SEM)장비를 활용 한 파면 관찰을 통해 적층 소재의 피로 파면을 분석, 고찰하였다. Fig. 10과 11에 나타난 바와 같이, Z, Y 방향 적층 시험편들의 피로 균열은 대부분 시편 표면부 에서 시작하여 시편 중앙부로 진전 후 최종 파단이 발 생하였다. 또한, wrought 소재의 피로 파괴 특성과 같 


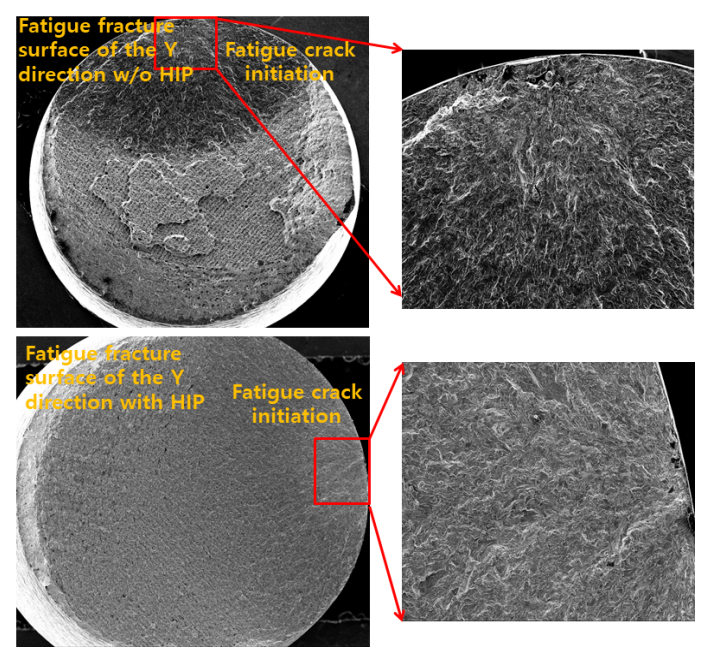

Fig. 10 SEM fractography of Y direction specimen

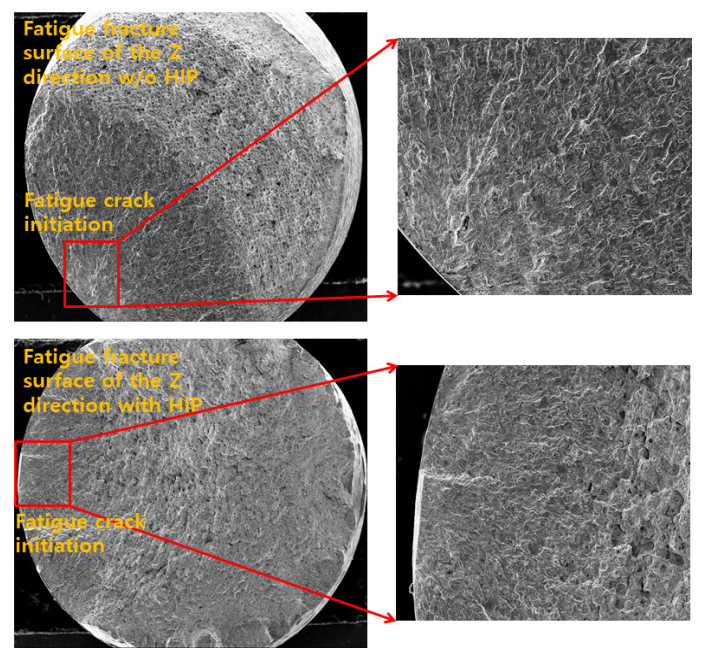

Fig. 11 SEM fractography of $Z$ direction specimen

이 연성 파괴 영역에서는 딤플(dimple) 구조가 확연히 나타났으며 피로 균열 진전 영역에서는 striation이 확 인되었다. 이때, 연성 파괴 영역에서는 일반적인 크기 의 딤플이 아닌 $1 \mu \mathrm{m}$ 정도의 작은 딤플들이 관찰되었다.

각 방향의 피로 파면을 비교해보면, Fig. 12 와 같이 연성 파괴 영역에서 일정 간격의 층들이 선명하게 나타 났으며 벌집(honeycomb)형상 파면이 공통적으로 관찰되 었다. 또한, $\mathrm{Y}$ 방향 적층 소재의 개재물(inclusion)들 의 간격과 공극(void)의 크기가 $\mathrm{Z}$ 방향 적층 소재의 간격과 공극보다 작음을 알 수 있다. HIP 공정 적용 시험편의 경우, 연성파면의 딤플은 기존 시험편의 딤플 크기보다 증가하는데, 이는 강도 저하 및 연신율의 증 가와 관계가 있다. 이를 통해, 파면 분석의 결과가 적 층 소재 인장 시험의 결과와 일치함을 알 수 있다.

Fig. 9의 S-N curve들을 살펴보면 $\mathrm{Y}$ 방향 적층 소 재의 S-N curve 기울기가 고하중 영역에서의 짧은 수

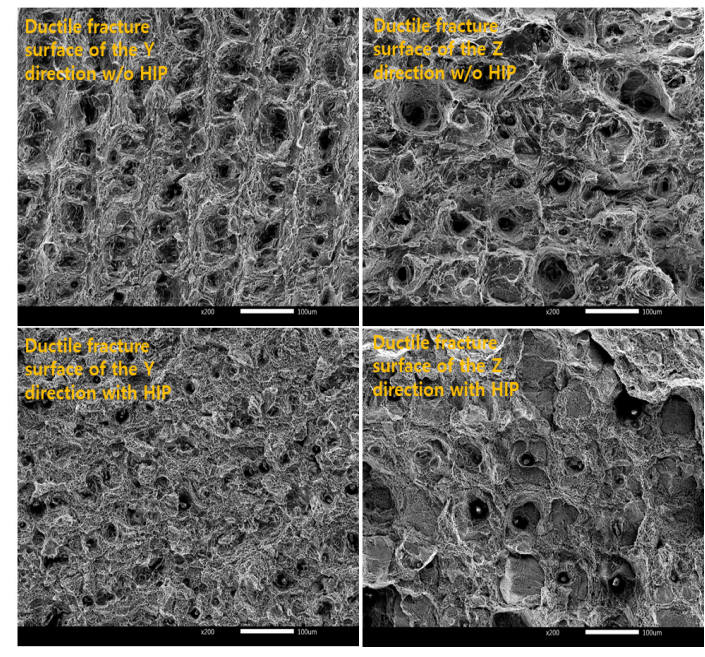

Fig. 12 SEM fractography of ductile fracture surface

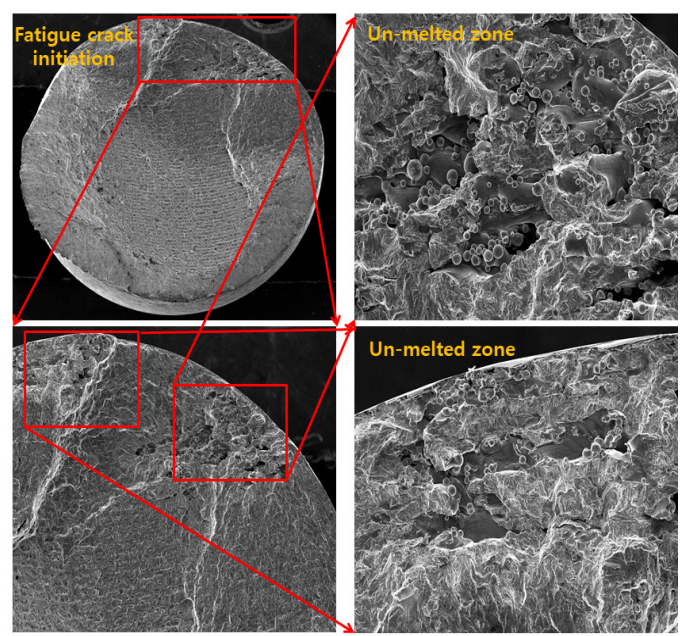

Fig. 13 Un-melted zone of test specimen at high load region

명에 의해 Z 방향의 S-N curve 기울기보다 커지는 것 을 알 수 있다. 이를 분석하기 위해 고하중 영역에서 파단된 시편의 파면을 분석하였다. Fig. 13 과 같이, 시편 파면에서 분말이 녹지 않고 고착되어 있는 un-melted zone이 관찰되었으며, 이때 un-melted zone 분말의 사이즈는 수십 $\mu \mathrm{m}$ 으로 다양한 크기의 사이즈를 가지는 것을 확인하였다. 즉, 이러한 녹지 않는 다양한 크기의 분말이 만든 un-melted zone이 내부 노치 역할을 하 여 피로 수명을 감소시켰을 것으로 판단되며, 이를 고 려하여 S-N curve를 보정한다면 Y 방향의 피로 강도 가 Z 방향의 피로 강도보다 높아질 것으로 예상된다.

\section{5. 결 론}

본 연구에서는 레이저 $\mathrm{PBF}$ 로 제작된 $\mathrm{SS} 316 \mathrm{~L}$ 적 
층 소재의 기계적 강도와 피로 특성을 평가하였다. 적 층방향과 후처리 공정 적용에 따른 강도 변화를 분석하 였으며, 주요 결론을 아래에 정리하였다.

1) $\mathrm{Z}$ 방향으로 적층한 소재의 항복, 인장 강도가 $\mathrm{Y}$ 방향 적층 소재의 강도들보다 낮음을 확인하였다. 이는, 적층방향에 따라 강도가 변한다는 것을 의미하며 적층 부품의 건전성을 확보하기 위해서는 적층 방향에 따른 평가가 필수적일 것으로 판단된다.

2) $\mathrm{HIP}$ 공정 적용에 의해 SS 316L 적층 소재의 항 복, 인장강도와 연신율의 현저한 변화가 발생하였다. 따라서, 후처리 공정이 적용된 적층 소재의 신뢰성 확 보를 위해서는 기계적 강도와 미세조직 변화에 대한 추 가적인 분석이 필요할 것으로 판단된다.

3) 소재의 적층방향에 따라 피로 강도의 미미한 차이 가 발생하였으며, 이는 적층소재의 인장 특성과 유사함 을 확인하였다. HIP 공정이 적용된 적층 소재의 피로 강도는 기존 적층소재의 강도보다 낮으며, 적층방향에 의한 피로 강도 차이가 사라짐을 알 수 있다.

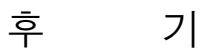

본 연구는 산업통상자원부(MOTIE)와 한국에너지기 술평가원 $(\mathrm{KETEP})$ 의 지원을 받아 수행한 연구 과제입 니다. (No.20161510200340)

ORCID: Dongiin Oh: https://orcid.org/0000-0002-6685-0169

\section{References}

1. Y. M. Wang, T. Voisin, J. T. Mckeown, J. Ye and N. P. Calta, Additively manufactured hierarchical stainless steels with high strength and ductility, Nat. Mater. 17 (2018), 63-70. https://doi.org/10.1038/nmat5021

2. J. H. Byun and S. M. Cho, Trend of metal 3D printing by Welding, J. Weld. Join. 34 (4) (2016), 1-8. https://doi.org/10.5781/JWJ.2016.34.4.1

3. D. K Kim and W. Woo, Neutron diffraction measurement of residual stress in high melting point metals processed by 3D printing, J. Weld. Join. 36 (6) (2018), 14-20. https://doi.org/10.5781/JWJ.2018.36.6.3

4. O. Fergani, A. Bratli Wold, F. Berto, V. Brotan and M. Bambach, Study of the effect of heat treatment on fatigue crack growth behaviour of 316L stainless steel produced by selective laser melting, Fatigue Fract. Eng. M. 41 (2018), 1102-1119. https://doi.org/10.1111/ffe.12755
5. W. E. Frazier, Metal additive manufacturing: A review, J. Mater. Eng. Perform. 23 (6) (2014), 1917-1928. https://doi.org/10.1007/s11665-014-0958-z

6. A. Yadollashi and N. shamsaei, Additive manufacturing of fatigue resistant materials: Challenges and opportunities, Int J. Fatigue. 98 (2017), 14-31. https://doi.org/10.1016/j.ijfatigue.2017.01.001

7. T. H. Lee, M. J. Kang, J. H. Oh and D. H. Kam, Parametric Study of STS 316L deposition with arc and wire additive manufacturing, J. Weld. Join. 36(3) (2018), 23-30. https://doi.org/10.5781/JWJ.2018.36.3.4

8. J. C. Yoon, M. G. Lee, C. Y. Choi, D. H. Kim, M. S. Jeong, Y. J. Choi and D. H. Kim, Evaluation of Microstructure and Mechanical Properties in 17-4PH Stainless Steels Fabricated by PBF and DED Processes, J. Korean Soc. of Manuf. Process Eng. 17 (2) (2018), 83-88. https://doi.org/10.14775/ksmpe.2018.17.2.083

9. J. Suryawanshi, K. G. Prashanth and U. Ramamurty, Mechanical behavior of selective laser melted $316 \mathrm{~L}$ stainless steel, Mat. Sci. Eng. A-Struct. 696 (2017), 113-121. https://doi.org/10.1016/j.msea.2017.04.058

10. J. J. Lewandowski and M. Seifi, Metal additive manufacturing: A review of mechanical properties, Annu. Rev. of Mater. Res. 46 (2016), 151-186. https://doi.org/10.1146/annurev-matsci-070115-032024

11. ASTM F3184-16, Standard specification for additive manufacturing stainless steel alloy (UNS S31603) with powder bed fusion, American Society for Testing and Materials (ASTM) (2016).

12. ASTM E8/E8M-16a, Standard test methods for tension testing of metallic materials, American Society for Testing and Materials (ASTM) (2016).

13. ASTM 466-15, Standard practice for conducting force controlled constant amplitude axial fatigue tests of metallic materials, American Society for Testing and Materials (ASTM) (2015).

14. A. Belyakov, Y. Sakai, H. Miura, R. Kaibyshev and K. Ysuzaki, Continuous recrystallization in austenitic stainless steel after large strain deformation, Acta Mater. 50 (2002), 1547-1557. https://doi.org/10.1016/S1359-6454(02)00013-7

15. M. Naghizadeh and H. Mirzadeh, Microstructural evolutions during annealing of plastically deformed AISI 304 austenitic stainless steel: martensite reversion, grain refinement, recrystallization, and grain growth, Metall. Mater. Trans. A. 47(8) (2016), 4210-4216. https://doi.org/10.1007/s11661-016-3589-1

16. E. S. Puchi-Cabrera, M. H. Staia, C. Tovar and E.A. Ochoa-Pérez, High cycle fatigue behavior of $316 \mathrm{~L}$ stainless steel, Int J. Fatigue. 30 (2008), 2140-2146. https://doi.org/10.1016/j.ijfatigue.2008.05.018 